\title{
Carotid stenting in Nepal: Our experience with two cases of carotid stenosis
}

\author{
Pravesh Rajbhandari $M S^{1}$ iD, Saujanya Rajbhandari $M D^{2}$ iD, Anish Neupane $M D^{3}$ iD, \\ Tariq Martin $\boldsymbol{M D}^{4}$ iD, Basant Pant $\boldsymbol{P h D}^{5}$ iD \\ 1,3,5 Department of Neurosurgery, Annapurna Neurological Institute and Allied sciences, Maitighar, Kathmandu, Nepal \\ ${ }^{2}$ Department of Neurosurgery, Hyogo College of Medicine, Nishinomiya, Japan \\ ${ }^{4}$ Department of Neurointervention, Narayana Superspeciality Hospital, Delhi, India
}

Date of submission: $1^{\text {st }}$ February 2021

Date of acceptance: $16^{\text {th }}$ August 2021

Date of publication: $1^{\text {st }}$ September 2021

\section{Abstract}

Carotid artery stenosis is one of the important risk factors for stroke. Carotid endarterectomy and carotid artery stenting are the available treatment options for managing carotid artery stenosis patients. The technology shift towards carotid artery stenting is promising due to its less invasive approach. Carotid artery stenting has become an alternative for surgically high-risk patients and high carotid lesions (lesions located at or above the second cervical vertebra). Here, we present two cases with carotid artery stenosis who were successfully treated with open-cell type carotid stent with distal filter embolic protection device.

Key words: Carotid artery stenting, Computed tomography angiography, Digital subtraction angiography, Embolic protection device, Infarction, Open cell carotid stent.

\section{Introduction}

Card arotid artery stenosis is a significant risk factor for stroke. Generally, stenosis $>50 \%$ or $>60 \%$ is clinically important due to the increased risk of stroke. Moreover, the prevalence of severe asymptomatic carotid artery stenosis $(>70 \%)$ is as high as $3.1 \%{ }^{1}$

Treatments for this condition include medical therapy, carotid endarterectomy (CEA), and more recently carotid artery stenting (CAS). CAS is shown to be a more effective treatment method for cases in which CEA carries a high

Access this article online
Website: https://www.nepjol.info/index.php/NJN
DOI: https://doi.org/10.3126/njn.v18i3.34684
HOW TO CITE
Rajbhandari P, Rajbhandari S, Neupane A, Martin T, Pant B.
Carotid stenting in Nepal: Our experience with two cases of
carotid stenosis. NJNS. 2021;18(3):44-8.

Address for correspondence:

Dr. Pravesh Rajbhandari

Department of Neurosurgery,

Annapurna Neurological Institute and Allied Sciences,

Maitighar, Kathmandu, Nepal.

E-mail: praveshreema@gmail.com

Phone: +9779851181497

Copyright (C) 2021 Nepalese Society of Neurosurgeons (NESON)

ISSN: 1813-1948 (Print), 1813-1956 (Online)

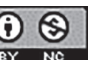

This work is licensed under a Creative Commons

Attribution-Non Commercial 4.0 International License. risk. Several studies have shown that periprocedural stroke is more common with CAS; however, myocardial infarction (MI) is more frequently associated with CEA. ${ }^{2}$ The occurrence of intraoperative embolization is one of the major risk factors of CAS. This obstacle has been tackled in recent years with advancements in devices, stent design, and better use of embolic protection devices (EPDs).

Here, we report two cases with carotid artery stenosis who were successfully treated with open-cell type carotid stent with distal filter embolic protection device. Informed consent was taken for the case report.

\section{Case 1}

A 60-year-old lady presented with weakness of the right side of the body. She was recently diagnosed with diabetes mellitus and was under medication. Computed Tomography (CT) scan of the head showed hypodensity in bilateral cerebral white matter. Carotid doppler depicted right near complete and left $72 \%$ stenosis in the internal carotid artery (ICA) on North American Symptomatic Carotid Endarterectomy Trial (NASCET) criteria. CT angiography of carotid vessels with the circle of Willis revealed complete occlusion of the right internal carotid artery and short segment occlusive thrombosis of the left ICA. We carefully explained to the patient and her family about treatment plans, surgical or endovascular treatment. Considering the non-invasiveness of the procedure, the patient hoped to receive CAS. Therefore, we planned to perform CAS. The patient was administered aspirin 150 $\mathrm{mg}$ /day and clopidogrel $150 \mathrm{mg} /$ day, one week before 


\section{Endovascular management of carotid stenosis}

the procedure. Under local anesthesia, the right femoral artery was accessed using an $8 \mathrm{~F}$ femoral sheath. 5000 IU heparin was administered intravenously to prolong activated clotting time (ACT) to at least 250s. The left common carotid artery (CCA) was accessed with a 0.035 -inch guidewire followed by a $5 \mathrm{~F}$ vertebral catheter supported by an $8 \mathrm{~F}$ guiding catheter (Super Arrow-Flex; Teleflex, NC)) coaxially. Digital subtraction angiography (DSA) confirmed occlusion of the left ICA (Figure 1).

The FilterWire EZ (BSC, Natick, MA) was placed across the stenotic lesion and deployed in the distal ICA (Figure 2a). Angiography was done to confirm the antegrade blood flow after deployment of Filter Wire EZ. Pre-stenting dilatation was done using a percutaneous transluminal angioplasty balloon $3.5 \mathrm{~mm}$ x $20 \mathrm{~mm}$ for 30 seconds. Following this self-expanding open-cell type carotid stent (Precise stent; $5 \mathrm{~mm}$ x $30 \mathrm{~mm}$; Cordis, Hialeah, Fla) was deployed on the stenotic region (Figure 2b).

Stenting was followed by post-stenting dilatation using a $4 \mathrm{~mm}$ × $20 \mathrm{~mm}$ percutaneous transluminal angioplasty balloon for about 30 seconds at the narrowest area.

After the procedure, mean arterial pressure (MAP) was closely monitored and maintained to $80-90 \mathrm{~mm}$ of $\mathrm{Hg}$. There was no new neurological deficit after the procedure and post-procedure CT scan showed no new cerebral ischemic lesions. The patient was placed on dual antiplatelet therapy (aspirin $100 \mathrm{mg}$ and clopidogrel $75 \mathrm{mg}$ ) for one-month following which clopidogrel was stopped and aspirin was continued for life. The patient was followed up after one month and six months. Although her initial right-sided weakness slightly remained, she did not experience any new focal neurological deficit during the follow-up. The patient is planned to be followed up annually.

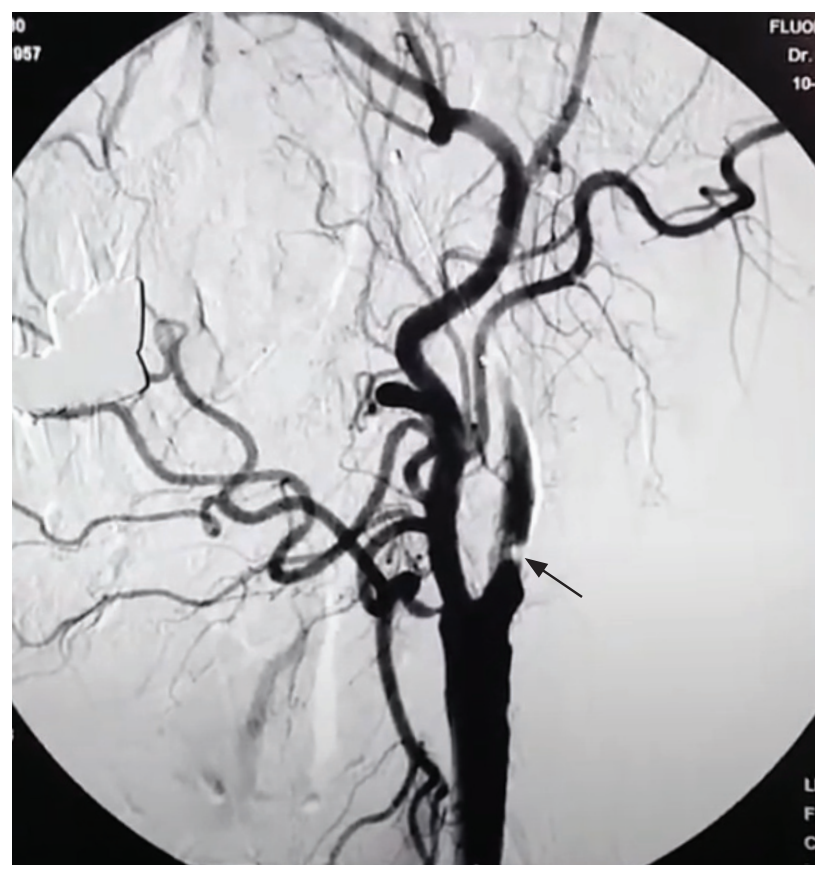

Figure 1: Left common carotid angiography showing left internal carotid artery stenosis (arrow).
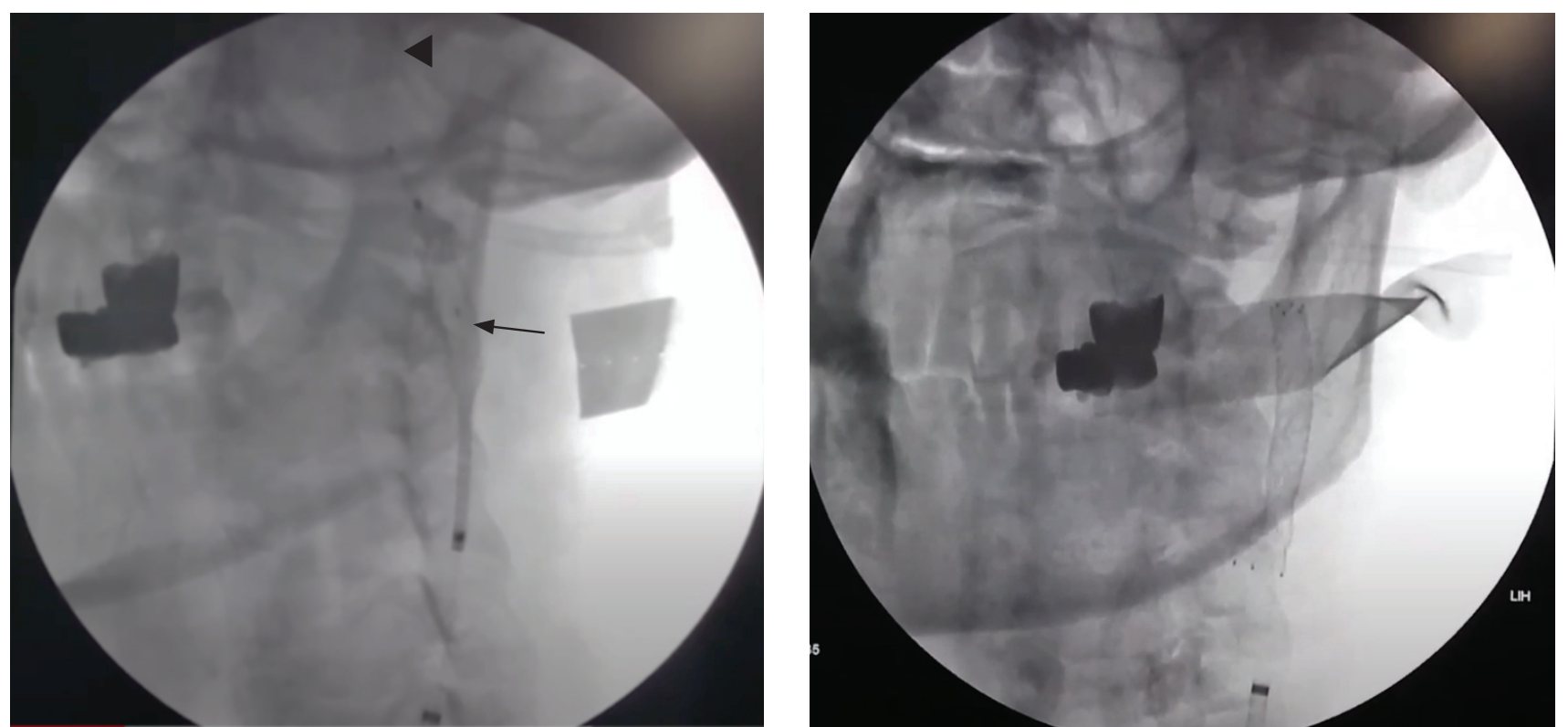

Figure 2a: Partially deployed carotid artery stent (arrow) and distally placed embolic protection device (FilterWire EZ) (arrowhead).

2b: Completely deployed carotid artery stent. 


\section{Case 2}

A 60-year-old male presented with a visual deficit. CT showed infarction in the right occipito-parietal region. CT angiography revealed $65 \%$ occlusion of right proximal ICA. There were no stenotic regions in posterior circulation. The patient underwent carotid artery stenting with all preventive techniques as described above. Postoperative angiography showed no embolism. The patient's postoperative course was uneventful. CT head revealed no changes as compared to the pre-operative scan. The patient was followed up and kept on antiplatelet medications as described in the above case. The patient did not have any new neurological deficit at the 6-month follow-up and is planned to be followed up annually.

\section{Discussion}

Carotid artery stenosis is accountable for about $20 \%$ of strokes and typically occurs at the bifurcation of the internal and external carotid arteries. ${ }^{3,4}$ CAS is emerging as an alternative to CEA to treat carotid stenosis patients. Several trials have demonstrated the benefit of CAS especially in those patients who have a high risk for surgical management. Moreover, its use in surgically inaccessible lesions such as high lesions at or above the upper margin of the second cervical vertebra has shown the promising potential of CAS. ${ }^{5}$

Numerous randomized controlled trials (RCTs) have attempted to assess which treatment is better. The CREST trial compared CEA to CAS in a cohort of both symptomatic and asymptomatic patients. ${ }^{6}$ The trial demonstrated that the periprocedural stroke/death/MI rate did not differ significantly between the two groups. Although individual rates of periprocedural strokes occurred with CAS, however, there were fewer periprocedural MIs. While cranial nerve injury was more common with CEA. Longterm results showed no significant difference was seen between the two treatment groups concerning restenosis or need for revascularization. The SAPPHIRE trial compared CAS to CEA in "high risk" patients (defined as clinically relevant cardiac disease, extreme pulmonary disease, contralateral carotid occlusion or laryngeal nerve palsy, prior radical neck surgery or cervical radiotherapy (c-XRT), persistent stenosis after CEA, and age $>80){ }^{7,8}$ Most of the patients included in this study were asymptomatic stenosis. This trial also reported the non-inferiority of CAS with respect to periprocedural death/stroke/MI or postprocedural death/ipsilateral stroke. Similarly, the Asymptomatic Carotid Trial (ACT-1) compared CEA and CAS in asymptomatic patients. The trial reported CAS as non-inferior to CEA concerning combined periprocedural death/stroke/MI or ipsilateral stroke within 1 year $(3.8 \%$ vs $3.4 \%$, respectively). However, several clinical trials that compared CAS to CEA in symptomatic carotid artery stenosis (ICSS, EVA-3S study, and SPACE study) failed to demonstrate the non-inferiority of CAS over CEA. ${ }^{9-11}$ The CAS related complications have been significantly reduced with time due to the increasing skill of surgeons, use of embolic protection devices (EPDs), emerging endovascular techniques, and proper patient selection. Thus, results from earlier RCTs which showed the ineffectiveness of CAS can be less applicable.

Embolic complications of CAS have triggered the development of EPDs. Various EPDs have been created using filters and guidewire-attached balloons. The commonly used ones are distal filter embolic protection devices and proximal embolic protection devices. ${ }^{12} \mathrm{~A}$ multicentre prospective registry of 1483 patients revealed that patients managed with EPDs had lower rates of ipsilateral stroke $(1.7 \%$ vs $4.1 \% ; P=0.007)$ and non-fatal strokes/deaths $(2.1 \%$ vs $4.9 \% ; P=0.004) .{ }^{13}$ In our case, we used filter embolic protection devices for cerebral protection during the procedure to avoid any inadvertent complication. Filter embolic protection devices have been shown to minimize the rate of occurrence of ischemic lesions and lower the symptomatic ischemic complications. ${ }^{14}$

Stents for CAS can be classified as open/closed cell, bare metal, or covered and tapered and non-tapered. The selection of a stent depends on the indication and characteristics of the carotid plaque (soft or hard plaque). We reported the use of open-cell stents in the abovepresented cases. Open-cell stents can adapt well to the shape of the vessel and are easier to deploy. However, it physically covers less of the target plaque, which poses the risk of distal embolization as atherosclerotic plaque can prolapse through the stent struts. Therefore, closedcell stents are preferably used in patients with softer plaque. As it has the advantage of preventing plaque protrusion from the stent struts. However, the closedcell stent is relatively harder to deploy and may kink the vessel if placed inappropriately. Bare metal stents are metal scaffolds that are directed to prevent smooth muscle cell proliferation (and thus restenosis). Tapered stents are characterized by a narrow diameter distally and larger diameter proximally. This design mimics the progressive narrowing of the ICA. Studies have shown that patients treated with tapered stent have a lesser chance of restenosis in the follow-up. Most of the current attention is focused on a novel carotid stent design- a double-layer mesh stent which structure is characterized by a micromesh layer for plaque coverage mounted over a self-expanding nitinol layer for scaffolding, offering the flexibility comparable to the open cell design stent.

Stent thrombosis is a dreaded complication that can be encountered following CAS. Several guidelines recommend administration of DAPT pre-and post- 
procedure along with antihypertensives, beta-blockers, and lipid-lowering agents. However, no large RCTs evaluating antiplatelet therapy in CAS have been done. Statins have been proven to decrease periprocedural stroke, death, and MI risk. Hyperperfusion syndrome (HPS) is another rare but potentially devastating complication after carotid revascularization. ${ }^{15}$ Carotid artery stenosis patients in power stage II have a high risk for posttreatment hyperperfusion syndrome (HPS). Yoshimura et al demonstrated staged angioplasty before carotid artery stenting reduced the HPS in patients in powers stage II evaluated by using SPECT (Single Photon Emission Computed Tomography). ${ }^{16}$

Patient selection is especially important in CAS to reach a favorable outcome. Difficult arch anatomy and advanced atherosclerotic changes of the lesion or alongside the access route might excessively increase the risk of CAS. ${ }^{17}$ Unstable components of plaque such as lipid-rich necrotic core and plaque with intraplaque hemorrhage are one of the major risk factors of stroke following CAS. MRI can offer excellent imaging of carotid plaque to help detection of these vulnerable plaques. The combination of 'T1-high and time of flight (TOF)-low intensity' suggests lipid-rich plaque and 'T1-high and TOF-high intensity' suggests intraplaque hemorrhage. The circumferential calcification in the plaque and the wall of the carotid artery is also a lesion resisting dilatation with balloons and stents which is detected in plain axial CT.

With the progressive development in the field of neuroendovascular therapy in Nepal, CAS can offer an alternative treatment option in a patient with carotid artery stenosis. ${ }^{18}$

\section{Conclusion}

In recent years, CAS has become an alternative treatment for carotid artery stenosis. It has improved tremendously with newer equipment, stent design, and EPD. Improved outcomes can be further achieved with proper patient selection, procedural strategy, and increased experience. In the future, larger RCTs should be conducted to establish consistent practice guidelines for CAS.

Conflict of Interest: None

Source(s) of support: None

\section{References}

1. De Weerd M, Greving JP, Hedblad B, Lorenz MW, Mathiesen EB, O'leary $\mathrm{DH}$, et al. Prevalence of asymptomatic carotid artery stenosis in the general population: An individual participant data metaanalysis. Stroke. 2010;41(6):1294-7. https://doi. org/10.1161/STROKEAHA.110.581058
2. Lamanna A, Maingard J, Barras CD, Kok HK, Handelman G, Chandra RV, et al. Carotid artery stenting: Current state of evidence and future directions. Acta Neurologica Scandinavica. 2019:318-33. https://doi.org/10.1111/ane.13062

3. Sardar P, Chatterjee S, Aronow HD, Kundu A, Ramchand P, Mukherjee D, et al. Carotid artery stenting versus endarterectomy for stroke prevention: A meta-analysis of clinical trials. J Am Coll Cardiol. 2017;69(18):2266-75. https://doi.org/10.1016/j. jacc.2017.02.053

4. Bonati LH, Lyrer P, Ederle J, Featherstone R, Brown MM. Percutaneous transluminal balloon angioplasty and stenting for carotid artery stenosis. Cochrane Database Syst Rev. 2012;(9). https://doi. org/10.1002/14651858.CD000515.pub4

5. Gray WA, White HJ, Barrett DM, Chandran G, Turner R, Reisman M. Carotid stenting and endarterectomy. Stroke. 2002;33(4):1063-70. https://doi.org/10.1161/ hs0402.105304

6. Brott TG, Howard G, Roubin GS, Meschia JF, Mackey A, Brooks W, et al. Long-term results of stenting versus endarterectomy for carotid-artery stenosis. N Engl J Med. 2016;374(11):1021-31. https://doi.org/10.1056/NEJMoa1505215

7. Yadav JS, Wholey MH, Kuntz RE, Fayad P, Katzen BT, Mishkel GJ, et al. Protected carotid-artery stenting versus endarterectomy in high-risk patients. N Engl J Med. 2004;351(15):1493-501. https://doi. org/10.1056/NEJMoa040127

8. Gurm HS, Yadav JS, Fayad P, Katzen BT, Mishkel GJ, Bajwa TK, et al. Long-term results of carotid stenting versus endarterectomy in high-risk patients. N Engl J Med. 2008;358(15):1572-9. https://doi. org/10.1056/NEJMoa0708028

9. Featherstone RL, Dobson J, Ederle J, Doig D, Bonati LH, Morris S, et al. Carotid artery stenting compared with endarterectomy in patients with symptomatic carotid stenosis (international carotid stenting study): A randomised controlled trial with cost-effectiveness analysis. Health Technol Assess. 2016;20(20):1-94. https://doi.org/10.3310/hta20200

10. Mas JL, Trinquart L, Leys D, Albucher JF, Rousseau H, Viguier A, et al. Endarterectomy versus angioplasty in patients with symptomatic severe carotid stenosis (EVA-3S) trial: Results up to 4 years from a randomised, multicentre trial. Lancet Neurol. 2008;7(10):885-92. https://doi.org/10.1016/S14744422(08)70195-9

11. Eckstein HH, Ringleb P, Allenberg JR, Berger J, Fraedrich G, Hacke W, et al. Results of the StentProtected Angioplasty versus Carotid Endarterectomy (SPACE) study to treat symptomatic stenoses at 2 years: A multinational, prospective, randomised trial. 


\section{Rajbhandari et al}

Lancet Neurol. 2008;7(10):893-902. https://doi. org/10.1016/S1474-4422(08)70196-0

12. Giri J, Kennedy KF, Weinberg I, Hawkins BM, Press $\mathrm{MC}$, Drachman D, et al. Comparative effectiveness of commonly used devices for carotid artery stenting: An NCDR analysis (National Cardiovascular Data Registry). JACC Cardiovasc Interv. 2014;7(2):1717. https://doi.org/10.1016/j.jcin.2013.10.014

13. Zahn R, Mark B, Niedermaier N, Zeymer U, Limbourg $\mathrm{P}$, Ischinger $\mathrm{T}$, et al. Embolic protection devices for carotid artery stenting: Better results than stenting without protection? Eur Heart J. 2004;25(17):1550 8. https://doi.org/10.1016/j.ehj.2004.06.018

14. Takayama K, Taoka T, Nakagawa H, Myouchin K, Wada T, Miyasaka T, et al. Initial experience of carotid artery stenting using the Carotid WALLSTENT and FilterWire EZ in Japan. Jpn J Radiol. 2011;29(1):518. https://doi.org/10.1007/s11604-010-0518-X

15. Komoribayashi N, Ogasawara K, Kobayashi M, Saitoh $\mathrm{H}$, Terasaki $\mathrm{K}$, Inoue $\mathrm{T}$, et al. Cerebral hyperperfusion after carotid endarterectomy is associated with preoperative hemodynamic impairment and intraoperative cerebral ischemia. J Cereb Blood Flow Metab. 2006;26(7):878-84. https://doi.org/10.1038/sj.jcbfm.9600244

16. Yoshimura S, Kitajima H, Enomoto Y, Yamada K, Iwama T. Staged angioplasty for carotid artery stenosis to prevent postoperative hyperperfusion. Neurosurgery. 2009;64(3 SUPPL.):ONS 122-9. https://doi.org/10.1227/01.NEU.0000334046.41985. BB

17. Spacek M, Veselka J. Bovine arch, Archives of Medical Science. Termedia Publishing; 2012.166-7. https://doi.org/10.5114/aoms.2012.27297

18. Rajbhandari P, Neupane A, Rajbhandari S, Shrestha P, Acharya S, Shrestha R, Rajbhandari R, Sharma A, Upadhya S, Dhungel P, Matin T. Initial experience with aneurysm coiling in Nepal. Nepal Journal of Neuroscience. 2018 Sep;15(2):30-5. https://doi. org/10.3126/njn.v15i2.20986 